\title{
Indirect validation of a retrospective method of exposure assessment used in a nested case-control study of lung cancer and silica exposure
}

\author{
M Dosemeci, J K McLaughlin, J-Q Chen, F Hearl, M McCawley, Z Wu, R-G Chen, \\ K-L Peng, A-L Chen, S H Rexing, W J Blot
}

\begin{abstract}
Validations of retrospective methods of assessment used in occupational epidemiological studies have rarely been published. This study is an indirect validation of a quantitative retrospective assessment of exposure to silica used in a nested case-control study of lung cancer among workers at 29 metal mines and pottery factories in China. Indices of cumulative total dust and cumulative respirable dust were calculated by merging work histories with the historical exposure profile for each subject. To validate indirectly the methods of exposure assessment used in the study of lung cancer, trends for exposure response relation between the two indices of exposure to silica and risk of silicosis were evaluated with 376 patients with silicosis from the study population as the cases, and 1262 controls without silicosis for comparison. Age adjusted odds ratios (ORs) as a measure of risk of silicosis showed striking trends with both indices of exposure to silica. For cumulative respirable dust, the OR (95\% confidence interval) rose from $7.6(5 \cdot 1-11 \cdot 4)$ for low exposure to $20.0(13.2-30.6)$ for medium exposure, and to $51.7(31 \cdot 0-86.8)$ for high exposure. The strength of the association between exposure to silica and risk of silicosis suggests that the retrospective assessment of exposure used in the casecontrol study of lung cancer would accurately reflect an exposure response relation between silica and lung cancer, if it existed.
\end{abstract}

(Occup Environ Med 1994;51:136-138)

Validation of retrospective methods of exposure assessment is not a common practice in occupational epidemiological studies. Although some investigators have reported studies on validation of work histories used in epidemiological studies, ${ }^{1-10}$ few studies have been carried out to validate assessment methods for specific exposures. ${ }^{11-15}$ Recently, Ulfvarson has pointed out the importance of validation of information on exposure used in the establishment of a causal association between an occupational disease and an exposure. ${ }^{16}$

In this study we present an indirect validation method to evaluate the accuracy of a retrospective assessment of exposure used in a study of workers exposed to silica in China. ${ }^{17}$

\section{Methods}

The investigation was a multicentre collaborative study between the National Cancer Institute in Bethesda, Maryland, the National Institute for Occupational Safety and Health in Morgantown, West Virginia, and the Tongji Medical University, in Wuhan, China. Twenty nine mines and factories from five south central provinces in China were included in the study. A cohort of 68285 workers was assembled who were employed during the period 1 January 1972 to 31 December 1974 at eight pottery factories, one clay mine, 10 tungsten mines, six copper-iron mines, and four tin mines. The workers were followed up until 31 December 1989. There were 316 cases of lung cancer in men in the nested case-control study. From four to five randomly selected workers matched to the cases of lung cancer by age and mine or factory type served as controls. Details of the case-control study were reported elsewhere. ${ }^{17}$

A retrospective method of exposure assessment was carried out to estimate historical exposure to silica among the subjects in the case-control study of lung cancer. Available information on historical exposure included industrial hygiene records, changes in the production processes and control measures with time, and employment records. Factory records and monitoring results available since the 1950s were evaluated for information on total dust and respirable silica levels. A job title dictionary was developed for five major categories of activity (underground mining, open cast mining, ore separation processing, pottery production, and other supporting activities). There were 659 combinations of workplace and job title in the dictionary. Historical information on total dust monitoring data $(2 \cdot 1$ million individual measurements), and on changes in processes and control measures was collected for each combination of workplace and job title at intervals of two or three years starting from 1950. Over 14 calendar year periods of study, covering 38 years, there were 6805 silica exposed workplace/job title/calendar period combinations. As well as the information on exposure to dust and silica, limited information was available for recent years on potentially confounding exposures-namely, to radon, polycylic aromatic hydrocarbons (PAHs), asbestos, talc, nickel, arsenic, and cadmium. Assignment of exposure levels for total dust was carried out by local mine and factory 
Table Odds ratios for silicosis among pottery workers and miners by facility type

\begin{tabular}{|c|c|c|c|c|}
\hline \multirow[b]{2}{*}{ Type of workplace } & \multicolumn{4}{|c|}{ Odds ratios ${ }^{*}$ by exposure levels } \\
\hline & None & Low & Medium & High \\
\hline $\begin{array}{l}\text { Cumulative total dust: } \\
\text { Potteries } \\
\text { Tungsten mines } \\
\text { Iron-copper mines } \\
\text { Tin mines } \\
\text { All workplaces combined }\end{array}$ & $\begin{array}{l}1 \cdot 0(5 ; 121) \ddagger \\
1 \cdot 0(14 ; 258) \\
1 \cdot 0(6 ; 227) \\
1 \cdot 0(23 ; 233) \\
1 \cdot 0(48 ; 839)\end{array}$ & $\begin{array}{l}4 \cdot 6(1-17)+(10 ; 55) \\
10 \cdot 5(5-23)(31 ; 55) \\
7 \cdot 6(3-23)(17 ; 94) \\
6 \cdot 0(3-11)(42 ; 71) \\
6 \cdot 6(5-10)(100 ; 275)\end{array}$ & $\begin{array}{l}10 \cdot 4(3-39)(12 ; 31) \\
25 \cdot 9(11-63)(30 ; 22) \\
29 \cdot 3(10-95)(18 ; 24) \\
33 \cdot 1(16-72)(55 ; 16) \\
21 \cdot 1(14-32)(115 ; 93)\end{array}$ & $\begin{array}{c}9 \cdot 1(3-32)(13 ; 33) \\
68 \cdot 3(27-182)(51 ; 14) \\
157 \cdot 6(23-1441)(11 ; 3) \\
66 \cdot 9(22-220)(38 ; 5) \\
32 \cdot 1(20-51)(113 ; 55)\end{array}$ \\
\hline $\begin{array}{l}\text { Cumulative respirable silica: } \\
\text { Potteries } \\
\text { Tungsten mines } \\
\text { Iron-copper mines } \\
\text { Tin mines } \\
\text { All workplaces combined }\end{array}$ & $\begin{array}{l}1.0(10 ; 148) \\
1.0(3 ; 206) \\
1.0(15 ; 280) \\
1.0(14 ; 211) \\
1.0(42 ; 845)\end{array}$ & $\begin{array}{r}3 \cdot 9(2-10)(20 ; 71) \\
21 \cdot 2(6-97)(19 ; 69) \\
7 \cdot 4(3-16)(22 ; 56) \\
8 \cdot 9(4-19)(36 ; 64) \\
7 \cdot 6(5-11)(97 ; 260)\end{array}$ & $\begin{array}{l}6 \cdot 4(2-25)(6 ; 15) \\
57 \cdot 6(16-251)(40 ; 49) \\
18 \cdot 2(6-55)(11 ; 11) \\
23 \cdot 0(11-48)(68 ; 43) \\
20 \cdot 0(13-31)(125 ; 118)\end{array}$ & $\begin{aligned} 8 \cdot 1 & (1-46)(4 ; 6) \\
162 \cdot 0 & (44-711)(64 ; 25) \\
76 \cdot 9 & (7-2068)(4 ; 1) \\
73 \cdot 2 & (25-225)(40 ; 7) \\
51 \cdot 7 & (31-87)(112 ; 39)\end{aligned}$ \\
\hline
\end{tabular}

^Adjusted for age. $\nmid 95 \%$ confidence interval. $¥$ No of cases; No of controls. $p=0.000$ for trend across rows throughout.

hygiene and safety personnel. These assignments were then reviewed by Chinese and United States industrial hygienists.

Work histories were obtained for cases and their controls by abstracting their employment records from mine and factory records. These work histories were merged with the estimates of exposure to calculate the subjects' cumulative exposure to total dust and respirable free silica. Further details on procedures of exposure assessment are described elsewhere. ${ }^{18}$

To validate the method of assessment of exposure used in the case-control study of lung cancer, we examined the well established association between exposure to silica and silicosis. The rationale was that if silica exposure was assessed accurately for the study population, the relation between silicosis and silica exposure should be striking. If not, then the estimates used for identifying silica exposure in the case-control study of lung cancer are likely to be erroneous.

Since 1963, a national law required that workplaces in China with exposure to silica have a silicosis registry. Cases and controls with silicosis were thus identified, with the degree of silicosis classified by the International Labour Organisation (ILO) classification scheme for pneumoconiosis. ${ }^{19}$ From the original study subjects, we selected as the case group all persons with stage I-III silicosis excluding subjects with the diagnosis of suspected silicosis; the control group was composed of those subjects without silicosis and lung cancer.

We used age adjusted odds ratios (ORs) to measure the association between exposure to silica and silicosis. ${ }^{20}$ The Mantel extension test for trend, ${ }^{21}$ was used to measure the size of the linear trend between exposure to silica and silicosis. In the analysis, we used cumulative dust (none $=0-73 \cdot 3$; low $=73 \cdot 4-220 \cdot 5$; medium $=220 \cdot 6-338 \cdot 9$; and high $>338.9$ in $\left.\mu \mathrm{g} / \mathrm{m}^{3} / \mathrm{y}\right)$, and cumulative respirable silica (none $=0-8 \cdot 6 ;$ low $=8 \cdot 7-26 \cdot 2 ;$ medium = $26.3-63.0$; high $>63.0$ in $\mu \mathrm{g} / \mathrm{m}^{3} / \mathrm{y}$ ) as the measures of exposure.

\section{Results}

There were 376 cases with stages I, II, or III silicosis and 1262 controls free from silicosis. Of the study subjects $17 \%$ were from pottery factories (40 cases, 240 controls), $29 \%$ from tungsten mines (126 cases, 349 controls), $25 \%$ from iron-copper mines (52 cases, 348 controls), and $29 \%$ from tin mines (158 cases, 325 controls).

Results of the analysis of exposure to silica and risk of lung cancer by facility type have been previously presented. ${ }^{17}$ For pottery factories and iron-copper mines, non-significant and inconsistent positive associations were found between risk of lung cancer and exposure to silica for both cumulative total dust and cumulative respirable silica. In tungsten mines, both measures of exposure showed a significant but negative association between exposure to silica and risk of lung cancer. Among tin mine workers, a significant and positive trend in risk was found with increased exposure to silica. Cumulative measurements of exposure to respirable silica showed a more consistent trend than cumulative measurements of exposure to total dust. Other lung carcinogens, however, such as arsenic, radon gas, and PAHs were highly correlated with exposure to silica in tin mines. Because association patterns were inconsistent across facilities, it was concluded that the results of the nested case-control study of lung cancer provide only limited support for an aetiological association between exposure to silica and lung cancer. ${ }^{17}$

The table shows results of the indirect validation. Each type of workplace showed a very strong positive trend for risk of silicosis by level of exposure to silica for both exposure indices. All types of workplace showed a striking association between silicosis and exposure to silica, although for pottery factories the strength of the association was less than for the other types of workplace. Tungsten miners showed the strongest association between risk of silicosis and exposure to silica whereas the same estimates of exposure to silica among these miners were not positively associated with risk of lung cancer.

\section{Discussion}

In this study, we indirectly validated the method of assessment of occupational exposure used in a nested case-control study of lung cancer in China. Trends for exposureresponse relations between two indices (cumulative total dust and cumulative 
respirable silica dust) of exposure to silica and risk of silicosis were evaluated using 376 patients with silicosis as the case group from the same study population. Risk of silicosis showed strong trends with both exposure indices to silica for every type of workplace, indicating that the method of assessment is sufficiently reliable to detect the well established association between silica and silicosis.

Several occupational reports have compared the results of methods of exposure assessment used by various raters. These comparisons were carried out to measure the agreement between raters (either among industrial hygienist chemists, ${ }^{22-25}$ or among workers and industrial hygienists, ${ }^{26-28}$ between assessment methods ${ }^{29-31}$ between information sources, ${ }^{3-5111214}$ or between measures of exposure. ${ }^{32}$ Almost all comparisons were carried out on ranking (or estimates) of exposures rather than their effects on estimates of risk. Only Pershagen and Axelson, and Blair and Stewart, like us, used both relative risks of disease and occupational exposure ranking in the comparison. The strong trend between exposure to silica and risk of silicosis provides confidence in the validity of the method developed for the assessment of exposure to silica in our earlier case-control study of lung cancer.

1 Keating E, Paterson DG, Stone $\mathrm{CH}$. Validity of work histories obtained by interview. I Appl Psychol 1950;3: 6-11.

2 Baumgarten M, Siemiatycki J, Gibbs GW. Validity of work histories obtained by interview for epidemiologic work histories obtained by interview for ep

3 Coggon D, Pippard EC, Acheson ED. Accuracy of occu pational histories obtained from wives. $B r \subsetneq$ Ind Med pational histories

4 Lerchen ML, Samet JM. An assessment of the validity of questionnaire responses provided by a surviving spouse. Am $\mathcal{Y}$ Epidemiol 1986;123:481-9.

5 Rosenberg CR, Mulvihill MN, Fichbein A, Blum S. An analysis of the validity of self reported occupational histories using a cohort of workers exposed to PCBs. B f Ind Med 1987;44:702-10.

6 Stewart WF, Tonascia JA, Matanoski GM. The validity of questionnaire-reported work history in live respondents. questionnaire-reported work hist

7 Bond GG, Bodner KM, Sobel W, Shellenberger RJ, Flores GH. Validation of work histories obtained from Flores GH. Validation of work histories obtain

8 Bourbonnais R, Meyer F, Theriault G. Validity of self reported work history. Br f Ind Med 1988;45:29-32.

9 Rona RJ, Mosbech J. Validity and repeatability of selfreported occupational and industrial history from patients in EEC countries. Int $\mathcal{F}$ Epidemiol 1989;18: 674-9.

10 Brisson C, Vezina M, Bernard PM, Gingras S. Validity of occupational histories obtained by interview with female workers. Am 9 Ind Med 1991;19.523-30.

11 Pershagen G, Axelson $O$. A validation of questionnair information on occupational exposure and smoking. Scand $\Im$ Work Environ Health 1982;8:24-8.

12 Hertzman C, Teschke $K$, Dimich-Ward H, Ostry A Validity and reliability of a method for retrospective evaluation of chlorophenate exposure in the lumber industry. Am $\mathrm{F}$ Ind Med 1988;14:703-13.

13 Ahlborg GA Jr. Validity of exposure data obtained by questionnaire. Two examples from occupational reproductive

14 Joffe $M$. Validity of exposure data derived from a struc tured questionnaire. Am ₹ Epidemiol 1992;135:564-70.

15 Cloutier Y, Lagier F, Cartier A, Malo JL. Validation of an exposure system to particles for the diagnosis of occupational asthma. Chest 1992;102:402-7.

16 Ulfvarson U. Validation of exposure information in occupational epidemiology. Am $\mathscr{f}$ Ind Med 1992;21:125-32.

17 McLaughlin JK, Chen JQ Dosemeci M, Chen RA, Rexing SH, Wu ZE, et al. A nested case-control study of lung cancer among silica exposed workers in China. Br F Ind Med 1992;49:167-71.

18 Dosemeci M, Chen J-O, Hearl F, Chen R-G, McCawley M, Wu Z, McLaughlin JK, et al. Estimating historical exposure to silica among mine and pottery workers in the People's Republic of China. Am ₹ Ind Med (in press).

19 International Labour Organisation. Guidelines for the use of ILO international classification of radiographs of pneumo coniosis. Revised ed. Geneva: IIO, 1980.

20 Breslow NE, Day NE. Statistical methods in cancer research. I. The analyses of case-control studies. Lyon: International Agency for research on cancer, 1980.

21 Mantel N. Chi-square tests with one degree of freedom: extension of the Mantel-Haenszel procedure. Fournal of the American Statistical Association 1963;58:690-700.

22 Goldberg MS, Siemiatycki J, Gerin M. Inter-rater agreement in assessing occupational exposure in a case ment in assessing occupational exposure

23 Ciccone G, Vineas P. Inter-rater agreement in the assessment of occupational exposure to herbicides. Med La 1988;79:363-7.

24 Hawkins NC, Evans JS. Subjective estimation of toluene exposures: a calibration study of industrial hygienists. Applied Industrial Hygiene 1989;4:61-8.

25 Post W, Kromhout H, Heederik D, Noy D, Duijzentkunst RS. Semiquantitative estimates of exposure to methylene chloride and styrene: the influence of quantitative exposure data Hygiene 1991;6:197-204.

26 Kromhout H, Oostendorp Y, Heederik D, Boleij JSM Agreement between qualitative exposure estimates and quantitative exposud

27 Jarvholm B, Sanden A. Estimating asbestos exposure: comparison of methods. f Occup Med 1987;29:361-3.

28 Teschke K, Hertzman C, Dimich-Ward H, Ostry A, Blair J, Hershler R. A comparison of exposure estimates by worker raters and industrial hygienists. Scand $\mathcal{f}$ Wor Environ Health 1989;15:424-9.

29 Linet MS, Stewart WF, Van Natta ML, McCaffrey LD, Szklo M. Comparison of methods for determining occupational exposure in a case-control interview study of chronic lymphocytic leukemia. $f$ Occup Med 1987;29. 136-41.

30 Dosemeci M, Stewart PA, Blair A. Evaluating Occupation and Industry separately to assess exposure in case-con

31 Siemiatycki J, Dewar R, Richardson L. Cost and statistical power associated with five methods of collectin occupation exposure information for population-based case-control studies. Am $\mathcal{Y}$ Epidemiol 1989;130:1236-46.

32 Blair A, Stewart PA. Do quantitative exposure assessmen improve risk estimates in occupational studies of cancer? Am ₹ Ind Med 1992;21:53-63. 